\title{
Self-Objectification Among Physically Active Women ${ }^{1}$
}

\author{
Christy Greenleaf ${ }^{2}$
}

Objectification Theory (Fredrickson \& Roberts, 1997) was used to examine (a) the mediation effects of body shame and flow on the relationship between self-objectification and disordered eating, (b) age differences in self-objectification, body shame, flow, and disordered eating, (c) the prediction of physical activity from self-objectification, flow, body shame, and disordered eating, and (d) the relationships between self-objectification, flow, and physical activity. Participants were 394 women ages 18-64. Results revealed that (a) body shame mediated the relationship between self-objectification and disordered eating, (b) younger women reported higher levels of self-objectification, body shame, dieting, and several flow characteristics, (c) older women scored higher on the loss of self-consciousness subscale of the flow measure, and (d) self-objectification was a significant predictor of physical activity.

KEY WORDS: self-objectification; body image; disordered eating.

What impact does living in a culture that treats the female body as an object for consumption have on girls and women? Research has suggested that girls and women are negatively impacted by the constant onslaught of cultural messages that imply that the female body is a public domain for all to evaluate and "consume" (Bordo, 1993; Cusumano \& Thompson, 1997). One consequence of living in a society that objectifies the female body is that girls and women are socialized to self-objectify (i.e., to internalize an observer's view of one's own body) (Fredrickson \& Roberts, 1997). That is, girls and women learn to view their own bodies as objects.

Several researchers have examined the psychological and behavioral impact that self-objectification can have on women (e.g., Fredrickson \& Roberts, 1997; Gapinski, Brownell, \& LaFrance, 2003; McKinley \& Hyde, 1996; Roberts \& Gettman, 2004). Fredrickson and Roberts (1997) proposed

\footnotetext{
${ }^{1}$ This article is based on the author's doctoral dissertation, which was completed at the University of North Carolina at Greensboro under the direction of Daniel Gould.

${ }^{2}$ To whom correspondence should be addressed at Department of Kinesiology, University of North Texas, Health Promotion, and Recreation, P.O. Box 311337, Denton, TX 76203; e-mail: cgreenleaf@coe.unt.edu.
}

Objectification Theory as a feminist sociocultural model to conceptualize experiences unique to girls and women and related mental health issues that result from self-objectification. Self-objectification is hypothesized to have several psychological consequences in the lives of women, including (a) increased body shame, (b) increased appearance anxiety, (c) decreased experiences of flow states (i.e., being totally absorbed in an activity), and (d) decreased sensitivity to internal bodily cues. Subsequently, these psychological consequences can put women at risk for experiencing certain mental health dysfunction such as disordered eating, which was the focus of the present study. The overall aim of the present study was to examine disordered eating symptomology among two age groups of physically active women using the self-objectification, body shame, flow, and disordered eating components of the Objectification Theory framework.

To date, several aspects of Objectification Theory have been well tested. The hypothesized relationships between self-objectification, body shame, and disordered eating, for example, have been supported by the results of several studies (e.g., Fredrickson, Roberts, Noll, Quinn, \& Twenge, 1998; McKinley, 1999; McKinley \& Hyde, 1996; Noll \& Fredrickson, 1998; Tiggemann \& Slater, 2001). 
Specifically, findings have indicated that women who report higher levels of self-objectification also report increased body shame, as well as more disordered eating symptomology. Results have demonstrated both a direct (Muehlenkamp \& Saris-Baglama, 2002; Noll \& Fredrickson, 1998) and a mediated (Noll \& Fredrickson, 1998; Slater \& Tiggemann, 2002) relationship between self-objectification and disordered eating. Body shame, in particular, has been found to mediate this relationship (Noll \& Fredrickson, 1998; Slater \& Tiggemann, 2002). Given that these components of Objectification Theory have been supported in previous research, they were utilized in the present study.

Based on previous research, I also included the flow component of the model, which has yet to be well studied or understood within the Objectification Theory framework. Flow is often described as the feeling of being "in the zone" and is an intrinsically motivating experience. Csikszentmihaly (1990) and others (Jackson \& Csikszentmihalyi, 1999) have outlined 9 characteristics of flow experiences, including (a) a balance between the perceived challenge of the situation and the skill possessed to meet that challenge, (b) a merging of action and awareness, (c) having clear goals, (d) receiving unambiguous feedback, (e) concentration on task at hand, (f) a sense of control, (g) a loss of self-consciousness, (h) transformation of time, and (i) an autotelic (i.e., intrinsically motivating) experience (see Csikszentmihalyi, 1990, or Jackson \& Csikszentmihalyi, 1999, for more information on the characteristics of flow). One of the key elements of flow, and the one most relevant to the present study, is the loss of self-consciousness or self-awareness that results from being totally absorbed in the activity at hand. Fredrickson and Roberts (1997) suggested that self-objectification increases one's awareness of the self and how others perceive the self, thus creating a heightened self-consciousness and reducing flow experiences. In one of the few studies that has included flow in the Objectification Theory model, Tiggemann and Slater (2001) found a significant negative relationship between self-surveillance, a construct similar to self-objectification, and flow among former dancers. Former dancers who experienced higher levels of self-objectification were less likely to report flow experiences. Thus, there is initial evidence to support flow as an important construct in the Objectification Theory model. The study of flow experiences seems particularly relevant for sport and exercise research. Numerous researchers have found that ath- letes and exercisers report experiencing flow while engaged in their sport or physical activity (Jackson \& Csikszentmihalyi, 1999). The flow component was therefore included in the Objectification Theory model in the present study in order to expand on previous research.

A unique component of Fredrickson and Roberts' (1997) conceptual framework is that it also offers implications across the lifespan of women. They suggested that during midlife women have the chance to move out of the "objectification limelight" and reclaim an inner connection with their bodies. During midlife women may encounter situations or environments in which they feel less pressure to conform to societal ideals of beauty, and thus have the opportunity to distance themselves from objectification and subsequently experience fewer of the negative psychological consequences of self-objectification (Fredrickson \& Roberts, 1997). Some research support for this hypothesis exists as Tiggemann and Lynch (2001) and McKinley (1999) have found that younger women report higher levels of self-objectification and self-surveillance than do older women. Related research has also provided some support for the contention that middle-aged women report fewer body image-related concerns than do college age women, which may suggest less self-objectification (Cash, Winstead, \& Janda, 1986; Pliner, Chaiken, \& Flett, 1990). However, other research has failed to demonstrate the negative relationship between body concerns and age (Altabe \& Thompson, 1993; Ben-Tovim \& Walker, 1994; Davis \& Cowles, 1991; Garner, 1997; Rozin \& Fallon, 1988; Tiggemann \& Lynch, 2001).

Similar to the unclear relationship between age and body concerns, there are inconsistent findings with regard to age differences in disordered eating symptomology. Some research has indicated that disordered eating symptomology does not differ between younger and older women (Rand \& Kuldau, 1991; Rozin \& Fallon, 1988), yet Tiggemann and Lynch (2001) found that older women reported less disordered eating than did younger women. In fact, Tiggemann and Lynch (2001) found that selfobjectification mediated the relationship between age and disordered eating. Thus, as Objectification Theory posits and initial research has suggested, it may be that the key factor that influences body concerns and disordered eating is the extent to which women self-objectify rather than age per se. Age differences were therefore examined in the present study to explore this possibility. 
If self-objectification, as opposed to age, is a key factor in disordered eating, then the Objectification Theory model examined here should be supported for both a younger, college-age group and an olderaged group.

The present study also incorporated two exploratory research questions. First, to extend previous Objectification Theory research, exercise behaviors were examined, and the question "Is self-objectification related to physical activity?" was addressed. As the theory suggests, women who self-objectify and experience other negative psychological consequences may be at a higher risk of experiencing dysfunctional mental health, such as disordered eating. To take this one step further, I sought to explore whether or not self-objectification, the psychological consequences of body shame and decreased flow experiences, and evidence of disordered eating predicted self-reported levels of physical activity. Previous researchers who have examined physical activity have used a self-presentational framework and suggested that body concerns may increase the motivation of some and decrease the motivation of others (Leary, 1992). For example, some individuals may be motivated to be physically active and exercise because they see it as a means of achieving a socially desirable physique, whereas other individuals may motivated to avoid physical activity and exercise because they do not want to put their "less than perfect" bodies on display. A similar line of reasoning may follow for self-objectification, and thus lead to the question of whether or not selfobjectification is related to physical activity.

The second exploratory research question addressed in the present study was "What is the relationship between self-objectification and frequency of flow experiences?" Physical exercise is an activity that seems to have the potential to present individuals with the opportunity to experience flow (i.e., to become totally absorbed in the physical activity and experience a loss of self-consciousness). However, exercise may also heighten individuals' selfconsciousness and awareness of their bodies (e.g., such that they experience social physique anxiety) (Focht \& Hausenblas, 2003; Martin Ginis, Jung, \& Gauvin, 2003). It seems logical, then, to explore the relationship between self-objectification and flow experiences during exercise.

In sum, the overall purpose of the present study was to examine self-objectification, flow experiences during physical activity, body shame, disordered eating, and physical activity among younger and older women using Objectification Theory as a guiding framework. The following specific research questions were addressed:

(a) Does self-objectification predict flow and body shame, which in turn mediate the relationship between self-objectification and disordered eating symptomology among younger and older women?

(b) Do older women differ from younger women in levels of self-reported self-objectification, body shame, flow, and disordered eating symptomology?

(c) Do self-objectification, flow, body shame, and eating disorder symptomology predict levels of physical activity among younger and older women?

(d) What are the relationships between selfobjectification, physical activity, and flow?

\section{METHOD}

\section{Participants}

Participants included a total of 394 physically active women. "Physically active" women included women who participated in purposeful exercise or physical activity for a minimum of 20 minutes at least 2 days per week. This operational definition of "physically active" was used to ensure that the participants in the study were engaging in purposeful physical activity on a fairly regular basis.

The younger age group sample consisted of 200 physically active female university students who ranged in age from 18 to 30 years $(M=20.96, S D=$ 2.42). The younger sample consisted of European Americans $(n=143,71.5 \%)$, African Americans $(n=38,19.0 \%)$, Native Americans $(n=6,3.0 \%)$, Latina Americans $(n=4,2.0 \%)$, Asian Americans $(n=3,1.5 \%)$, and others $(n=3,1.5 \%)$. Three participants did not report their ethnicity $(1.5 \%)$. Younger participants were recruited from activity classes and the student recreation center at a southeastern university.

The sample of older women consisted of 194 physically active women who ranged in age from 39 to 64 years $(M=48.95, S D=6.40)$. The older sample consisted of European Americans $(n=158$, $81.4 \%)$, Native Americans $(n=14,7.2 \%)$, African Americans $(n=5,2.6 \%)$, Latina Americans $(n=4$, $2.1 \%)$, Asian Americans $(n=2,1.0 \%)$, and others $(n=2,1.0 \%) ; 9$ participants $(4.6 \%)$ did not report 
their ethnicity. Older participants were recruited from the student recreation center of a southeastern university, from local health facilities, and from several health facilities and personal contacts outside the southeast.

\section{Measures}

\section{Demographics}

Demographic information was assessed via a demographic questionnaire that included questions about age, ethnicity, current height and weight, and ideal height and weight.

\section{Physical Activity}

The Aerobics Center Longitudinal Study Physical Activity Questionnaire (ACLS, Kohl, Blair, Paffenbarger, Macera, \& Kronenfeld, 1988) was used as a measure of physical activity. Participants report regular participation in 14 different activities over the last 3 months, along with the frequency, intensity, and duration of those activities. To determine participants' level of physical activity, a metabolic equivalent (MET) value was assigned for each activity. Estimates of energy expenditure were calculated based on the number of sessions per week, the number of minutes per session, and the MET value of the activity. Evidence for the validity of the ACLS has been demonstrated by Kohl et al. (1988) and by Oliveria, Kohl, Trichopoulos, and Blair (1996).

\section{Self-Objectification}

Self-objectification was measured using the Body Surveillance subscale of the Objectified Body Consciousness Scale (McKinley \& Hyde, 1996). Body surveillance refers to "viewing one's body as an outside observer" (McKinley, 1999, p. 760) and thus is conceptually similar to self-objectification. The Body Surveillance subscale (McKinley \& Hyde, 1996) consists of 8 items related to the extent to which a person thinks about how her body looks rather than how it feels. Participants respond to each item on a 7-point Likert scale that ranges from 1 (strongly disagree) to 7 (strongly agree), in addition, participants may respond "does not apply" if the item does not reflect the individual's experience (e.g., a participant may respond "does not apply" to an item regarding attempts to control weight if she is not trying to control her weight). The Body Surveillance subscale has shown adequate reliability and adequate internal consistency and 2-week test-retest reliability; it also has demonstrated good concurrent validity (see McKinley \& Hyde, 1996). In the present study, the Body Surveillance subscale exhibited adequate internal consistency, alpha $=.81$ (based on the total sample).

\section{Body Shame}

Body shame was measured using the Body Shame subscale of the Objectified Body Consciousness Scale (McKinley \& Hyde, 1996). Body shame refers to the internalization of cultural standards and the shame experienced when those standards are not met. The Body Shame subscale consists of 8 items related to feelings of shame associated with the failure of one's body to conform to an ideal (McKinley \& Hyde, 1996). Each item is rated on a 7-point Likert scale that ranges from 1 (strongly disagree) to 7 (strongly agree). In addition, participants may respond "does not apply." The Body Shame subscale has demonstrated adequate internal consistency and test-retest reliability (see McKinley \& Hyde, 1996). McKinley and Hyde (1996) also provided evidence for the concurrent validity of this subscale. The Body Shame subscale exhibited adequate internal consistency, alpha $=.85$, in the present study (based on the total sample).

\section{Flow}

The Flow Trait Scale (FTS, Jackson, Kimiecik, Ford, \& Marsh, 1998) was used to measure the frequency with which individuals typically experience flow during physical activity. The FTS is based on the Flow State Scale (FSS; Jackson \& Marsh, 1996). It consists of 36 items rated on a 5-point Likert scale that ranges from 1 (never) to 5 (always). The FTS has 9 subscales: challenge-skill balance (e.g., "I am challenged, but I believe my skills will allow me to meet the challenge"), action-awareness merging (e.g., "I make the correct movements without thinking about trying to do so"), clear goals (e.g., "I know clearly what I want to do"), unambiguous feedback (e.g., "I am aware of how well I have been performing"), 
concentration on task at hand (e.g., "My attention is focused entirely on what I am doing"), sense of control (e.g., "I have a sense of control over what I am doing"), loss of self-consciousness (e.g., "I am not concerned with what others may be thinking of me"), transformation of time (e.g., "Time seems to alter (either slows down or speeds up)"), and autotelic experience (e.g., "I really enjoy the experience"). The FTS has demonstrated adequate reliability (see Jackson et al., 1998). In the current study, the FTS subscales exhibited adequate internal consistency: challenge-skill balance (.84), actionawareness merging (.80), clear goals (.84), unambiguous feedback (.83), concentration on task at hand (.82), sense of control (.87), loss of self-consciousness (.85), transformation of time (.72), and autotelic experience (.83) (based on the total sample). Although most researchers use subscale scores, Jackson \& Eklund (2002) have stated that "it is recognized that global flow assessment is useful in addressing some research questions" (p. 146). For the purposes of the present study, a total flow score was calculated by summing item responses. The total test alpha was .94 .

\section{Disordered Eating}

To assess attitudes related to disordered eating, participants completed the Eating Attitudes Test (EAT-26; Garner, Olmsted, Bohr, \& Garfinkel, 1982). The EAT-26 includes three factors: dieting (i.e., avoidance of food and preoccupation with thinness), bulimia and food preoccupation (i.e., symptoms of bulimia), and oral control (i.e., self-control related to eating and perception of pressure to gain weight). The EAT-26 consists of 26 items. The EAT-26 was scored on a 6-point scale that ranges from 1 (never) to 6 (always). Following the procedures of Slater and Tiggemann (2002), untransformed scores were used in order to eliminate the skewed distribution obtained from the original scoring (such that the most disordered response receives 3-points, the second most disordered response receives 2-points, the third most disordered response receives 1-point, and the remaining three response options receives 0-points). The EAT-26 has shown good internal consistency and test-retest reliability (see Garner et al., 1982). In the present study, the dieting, bulimia and food preoccupation, and oral control subscales demon- strated adequate internal consistency, alpha $=.89$, alpha $=.72$, and alpha $=.62$, respectively. The total EAT-26 reliability was .90 (based on total sample).

\section{Procedure}

Participants were informed of their rights as participants, and they completed an informed consent form. Participants did not receive any compensation (e.g., extra credit, money) for their involvement in the study. Participants completed the instruments described above which were presented in 1 of 10 possible orders randomly determined by a number drawn during preparation of the instrument packets. All instruments were administered by the researcher or a research assistant familiar with the procedure. The return rate for completed surveys could not be calculated because some research assistants did not report the number of surveys handed out versus the number returned. Completion of the surveys took approximately 20-30 minutes.

\section{RESULTS}

\section{Characteristics of Sample}

The younger and older women reported engaging in a various modes of physical activity, on an average expending $38.23(S D=31.39)$ and 37.59 METS $(S D=50.93)$ per week, respectively. Younger participants reported significantly lower mean current and ideal weights than did older participants, $F(1,386)=$ $14.53, p<.001$ and $F(1,346)=12.74, p<.001$, respectively. Table I contains means and $S D$ of all measures.

\section{Relationships Between Variables}

\section{Younger Age Group}

Significant relationships were found between numerous variables (see Table II). Body mass index (BMI), self-objectification, and body shame were positively correlated with disordered eating. Physical activity was negatively correlated with disordered eating and positively related to flow. Flow was negatively correlated with self-objectification, body shame, and disordered eating. 
Table I. Group Means and $S D$

\begin{tabular}{|c|c|c|c|c|c|c|c|}
\hline & \multicolumn{2}{|c|}{ Younger age group } & \multicolumn{2}{|c|}{ Older age group } & \multirow[b]{2}{*}{ Sig. } & \multirow[b]{2}{*}{$\eta_{\mathrm{p}}^{2}$} & \multirow[b]{2}{*}{ Power } \\
\hline & Mean & $S D$ & Mean & $S D$ & & & \\
\hline Current weight & 139.60 & 23.83 & 150.00 & 29.66 & - & - & - \\
\hline Ideal weight & 127.85 & 15.37 & 134.10 & 17.30 & - & - & - \\
\hline Current height & 65.00 & 2.98 & 65.00 & 2.75 & - & - & - \\
\hline Body mass index (BMI) & 22.98 & 3.57 & 25.16 & 5.08 & - & - & - \\
\hline Self-objectification $^{a}$ & 4.67 & 1.15 & 4.06 & 1.00 & .001 & .076 & .999 \\
\hline Body shame $^{a}$ & 3.65 & 1.44 & 3.24 & 1.13 & .001 & .039 & .956 \\
\hline Flow (total) & 126.44 & 0.52 & 125.00 & 15.98 & - & - & - \\
\hline Challenge-skill balance ${ }^{a}$ & 14.81 & 2.52 & 13.78 & 2.42 & .002 & .028 & .866 \\
\hline Merging of action and awareness ${ }^{a}$ & 13.42 & 2.58 & 13.72 & 2.28 & .136 & .007 & .319 \\
\hline Clear goals ${ }^{a}$ & 15.28 & 2.97 & 15.10 & 2.18 & .614 & .001 & .080 \\
\hline Unambiguous feedback ${ }^{a}$ & 14.84 & 2.80 & 15.04 & 2.29 & .335 & .003 & .161 \\
\hline Concentration on task at hand ${ }^{a}$ & 13.46 & 2.96 & 13.70 & 2.16 & .340 & .003 & .159 \\
\hline Sense of control ${ }^{a}$ & 14.35 & 3.08 & 13.90 & 2.29 & .147 & .006 & .305 \\
\hline Loss of self-consciousness $^{a}$ & 11.92 & 3.33 & 13.09 & 3.05 & .001 & .036 & .937 \\
\hline Time transformation ${ }^{a}$ & 12.21 & 2.94 & 11.57 & 2.65 & .075 & .010 & .430 \\
\hline Autotelic experience ${ }^{a}$ & 15.58 & 2.73 & 14.93 & 2.53 & .042 & .012 & .531 \\
\hline Disordered eating (total) & 63.85 & 19.69 & 62.98 & 14.73 & - & - & - \\
\hline Dieting $^{a}$ & 35.07 & 13.18 & 33.34 & 8.55 & .014 & .018 & .696 \\
\hline Bulimia and food preoccupation $^{a}$ & 13.13 & 5.27 & 13.55 & 3.79 & .783 & .076 & .059 \\
\hline Oral control $^{a}$ & 15.81 & 4.93 & 15.45 & 4.04 & .659 & .195 & .073 \\
\hline
\end{tabular}

${ }^{a}$ Variables entered in MANCOVA.

\section{Older Age Group}

Among the older age group, numerous significant relationships were found (see Table III). Similar to the younger age group, BMI, self-objectification, and body shame were positively correlated with disordered eating. Self-objectification was negatively correlated with physical activity. Flow was negatively correlated with BMI, self-objectification, body shame, and disordered eating and positively correlated with physical activity.

\section{Mediators Between Self-Objectification and Disordered Eating}

Following the procedures outlined by Baron and Kenny (1986) and Holmbeck (1997) several

Table II. Correlations for Younger Age Group

\begin{tabular}{|c|c|c|c|c|c|c|c|c|}
\hline & \multirow[b]{2}{*}{ BMI } & \multirow[b]{2}{*}{ Self-obj. } & \multirow[b]{2}{*}{$\begin{array}{l}\text { Body } \\
\text { shame }\end{array}$} & \multirow[b]{2}{*}{$\begin{array}{c}\text { Physical } \\
\text { activity }\end{array}$} & \multicolumn{4}{|c|}{ Disordered eating } \\
\hline & & & & & Total & Dieting & Bulimia & $\begin{array}{c}\text { Oral } \\
\text { control }\end{array}$ \\
\hline BMI & - & .00 & $.15^{*}$ & .02 & $.24^{* *}$ & $.28^{* *}$ & $.27^{* *}$ & -.14 \\
\hline Self-objectification & & - & $.58^{* *}$ & -.12 & $.57^{* *}$ & $.55^{* *}$ & $.37^{* *}$ & $.18 *$ \\
\hline Body shame & - & - & - & .06 & $.69^{* *}$ & $.71^{* *}$ & $.58^{* *}$ & $.32^{* *}$ \\
\hline Physical activity & - & - & - & - & $.18^{*}$ & $.18^{*}$ & $.18^{*}$ & .08 \\
\hline Flow-total FTS & -.05 & $-.28^{* *}$ & $-.28^{* *}$ & .02 & $-.26^{* *}$ & $-.21^{* *}$ & $-.27^{* *}$ & -.09 \\
\hline Challenge-skill balance & -.11 & $-.18^{* *}$ & $-.25^{* *}$ & .01 & $-.20^{* *}$ & $-.15^{*}$ & $-.26^{* *}$ & -.07 \\
\hline Merging of action and awareness & -.06 & -.09 & -.13 & -.04 & -.12 & -.07 & -.13 & -.10 \\
\hline Clear goals & -.04 & $-.17^{*}$ & $-.21^{* *}$ & -.01 & $-.18^{*}$ & $-.16^{*}$ & $-.23^{* *}$ & -.03 \\
\hline Unambiguous feedback & -.04 & $-.22^{* *}$ & $-.27^{* *}$ & .04 & $-.24^{* *}$ & $-.23^{* *}$ & $-.28^{* *}$ & -.00 \\
\hline Concentration & -.06 & $-.28^{* *}$ & $-.21^{* *}$ & -.02 & $-.25^{* *}$ & $-.20^{* *}$ & $-.28^{* *}$ & -.05 \\
\hline Sense of control & -.01 & $-.24^{*}$ & $-.31^{* *}$ & -.05 & $-.31^{* *}$ & $-.25^{* *}$ & $-.32^{* *}$ & $-.14 *$ \\
\hline Loss of self-consciousness & -.05 & $-.48^{* *}$ & $-.40^{* *}$ & .05 & $-.39^{* *}$ & $-.35^{* *}$ & $-.30^{* *}$ & $-.23 *$ \\
\hline Time transformation & -.01 & -.01 & .03 & .08 & -.13 & .11 & $-.15^{*}$ & -.11 \\
\hline Autotelic experience & -.01 & -.09 & -.06 & .05 & -.06 & -.01 & -.11 & -.01 \\
\hline
\end{tabular}

${ }^{*} p<.05 .{ }^{* *} p<.001$. 
Table III. Correlations for Older Age Group

\begin{tabular}{|c|c|c|c|c|c|c|c|c|}
\hline & \multirow[b]{2}{*}{ BMI } & \multirow[b]{2}{*}{ Self-obj. } & \multirow[b]{2}{*}{$\begin{array}{l}\text { Body } \\
\text { shame }\end{array}$} & \multirow[b]{2}{*}{$\begin{array}{l}\text { Physical } \\
\text { activity }\end{array}$} & \multicolumn{4}{|c|}{ Disordered eating } \\
\hline & & & & & Total & Dieting & Bulimia & $\begin{array}{c}\text { Oral } \\
\text { control }\end{array}$ \\
\hline BMI & - & .07 & $.31^{* *}$ & -.02 & $.30^{* *}$ & $.32^{* *}$ & $.36^{* *}$ & .04 \\
\hline Self-objectification & & - & .07 & $-.24^{* *}$ & $.33^{* *}$ & $.39^{* *}$ & $.22^{* *}$ & .10 \\
\hline Body shame & & & - & -.12 & $.59^{* *}$ & $.58^{* *}$ & $.54^{* *}$ & $.26^{* *}$ \\
\hline Physical activity & & & & - & -.13 & $-.17^{*}$ & -.10 & -.02 \\
\hline Flow-total FTS & $-.16^{*}$ & $-.18^{*}$ & $-.27^{* *}$ & $.18^{*}$ & $-.19^{*}$ & $-.20^{* *}$ & $-.41^{* *}$ & .05 \\
\hline Challenge-skill balance & $-.22^{* *}$ & -.12 & $-.22^{* *}$ & .08 & $-.19^{*}$ & $-.19^{* *}$ & $-.39^{* *}$ & .05 \\
\hline Merging of action and awareness & $-.16^{* *}$ & -.14 & $-.16^{*}$ & $.18^{*}$ & -.11 & -.12 & $-.28^{* *}$ & .05 \\
\hline Clear goals & $-.20^{* *}$ & -.06 & $-.20^{* *}$ & .11 & -.10 & -.08 & $-.27^{* *}$ & -.01 \\
\hline Unambiguous feedback & $-.21^{* *}$ & -.01 & $-.21^{* *}$ & .05 & -.14 & -.12 & $-.34^{* *}$ & .00 \\
\hline Concentration & $-.16^{* *}$ & $-.16^{*}$ & $-.16^{*}$ & .12 & -.12 & -.12 & $-.28^{* *}$ & .04 \\
\hline Sense of control & $-.23^{* *}$ & $-.16^{*}$ & $-.23^{*}$ & $.28^{* *}$ & $-.20^{* *}$ & $-.19^{* *}$ & $-.35^{* *}$ & .01 \\
\hline Loss of self-consciousness & $-.21^{* *}$ & $-.36^{* *}$ & $-.21^{*}$ & .13 & $-.16^{*}$ & $-.19^{*}$ & $-.14^{*}$ & -.07 \\
\hline Time transformation & .02 & $-.19^{*}$ & .02 & $.19^{*}$ & .05 & -.02 & -.02 & $.19^{*}$ \\
\hline Autotelic experience & $-.18^{*}$ & -.02 & $-.18^{*}$ & .09 & -.11 & -.09 & $-.31^{* *}$ & .00 \\
\hline
\end{tabular}

steps were taken to determine the extent to which body shame and flow mediated the relationship between self-objectification and disordered eating. Body shame and flow were proposed as mediators based on Objectification Theory (Fredrickson \& Roberts, 1997). Separate analyses were conducted on the younger and older samples. The initial step was to determine that relationships existed between (a) the independent (self-objectification) and the dependent variable (disordered eating), (b) the independent variable (self-objectification) and the potential mediators (body shame and flow), and (c) the poten- tial mediator variables (body shame and flow) and the dependent variable (disordered eating). This initial condition was established for both of the age samples (see Tables II and III).

Next, to determine the potential mediating effects of body shame and flow, a hierarchical regression was conducted for each sample with BMI, calculated using participants' self-reported height and weight, entered first as a covariate, followed by self-objectification, and then body shame and flow. Table IV shows the regression coefficients for both samples. A mediation effect is indicated

Table IV. Coefficients for Hierarchical Mediation Regression Analyses

\begin{tabular}{lcccccc}
\hline & \multicolumn{5}{c}{ Disordered eating } \\
\cline { 2 - 7 } Predictor variables & $R^{2}$ & $\Delta R^{2}$ & $B$ & $S E B$ & $\beta$ & Sig. \\
\hline Younger age group & & & & & & \\
Step 1. BMI & $.06^{* *}$ & .057 & 1.319 & 0.399 & 0.239 & .001 \\
Step 2. BMI & $.32^{* *}$ & .262 & 1.206 & 0.340 & .0218 & .001 \\
$\quad$ Self-objectification & & & 8.923 & 1.072 & 0.512 & .000 \\
Step 3. BMI & $.53^{* *}$ & .216 & 0.753 & 0.287 & 0.136 & .530 \\
$\quad$ Self-objectification & & & 3.302 & 1.097 & 0.190 & .010 \\
Body shame & & & 7.828 & 0.883 & 0.562 & .000 \\
Flow & & & -1.332 & 2.084 & -0.035 & .520 \\
Older age group & & & & & & \\
Step 1. BMI & $.06^{* *}$ & .065 & 0.775 & 0.231 & 0.256 & .001 \\
Step 2. BMI & $.17^{* *}$ & .105 & .0684 & .0226 & 0.226 & .003 \\
$\quad$ Self-objectification & & & 4.466 & 1.023 & 0.326 & .000 \\
Step 3. BMI & $.36^{* *}$ & .186 & 0.305 & 0.210 & 0.101 & .150 \\
$\quad$ Self-objectification & & & 2.374 & 0.970 & 0.173 & .020 \\
Body shame & & & 5.686 & 0.888 & 0.471 & .000 \\
Flow & & & -0.773 & 2.201 & -0.024 & .726 \\
\hline
\end{tabular}

${ }^{* *} p<.001$. 
when the effect of the independent variable (selfobjectification) is reduced with the inclusion of the mediator variables (body shame and flow). In the younger sample, the beta coefficient was reduced from .512 to .190 when body shame and flow were included. A Sobel test was conducted to determine the strength of the mediation of body shame (given that flow was not significant). For the younger group, the indirect effect of self-objectification on disordered eating via body shame was significant, $t=2.87$, $p<.004$. This mediational model accounted for $53 \%$ of the variance in disordered eating scores for the younger sample. In the older sample, the beta coefficient was reduced from .326 to .173 when body shame and flow were included. The indirect effect for body shame was significant, $t=2.20, p<.03$. This model accounted for $36 \%$ of the variance in disordered eating scores for the older sample. Thus, for both age samples, body shame was a significant partial mediator of the relationship between self-objectification and disordered eating.

\section{Age Group Differences}

A multivariate analysis of covariance (MANCOVA) was conducted to test for age differences in self-objectification, body shame, flow characteristics, and disordered eating symptomology with BMI as the covariate. A significant age effect was found, Wilks' Lambda $=.903, F(4,330)=8.814$, $p<.001, \quad \eta_{p}^{2}=.097$, power $=.999$. Follow-up univariate tests indicated age-group differences for self-objectification, as measured by the body surveillance subscale, $F(1,333)=27.50, p<.001$, and body shame, $F(1,333)=13.51, p<.001$. The younger participants reported significantly higher levels of self-objectification and body shame than did the older participants. In addition, group differences were found for the dieting subscale of the EAT-26, $F(1,333)=6.14, p<.05$, and the skillchallenge balance, $F(1,333)=9.46, p<.01$, loss of self-consciousness, $F(1,333)=12.26, p<.001$, and autotelic experience, $F(1,333)=4.18, p<.05$, subscales of the FTS. Women in the younger age group had higher dieting scores and scored higher on the skill-challenge balance and autotelic experience subscales of the FTS than the older women. Women in the older age group scored higher than those in the younger age group on the loss of self-consciousness subscale of the FTS. See Table I for group means and $S D$.

\section{Physical Activity}

To explore the extension of the Objectification Theory model to include physical activity, stepwise regression analyses were conducted to determine if and how self-objectification, flow, body shame, and disordered eating accounted for variance in physical activity (note: BMI was entered as a covariate). For the younger women, disordered eating and selfobjectification were significant predictors of physical activity and accounted for $9 \%$ of the variance. For the older women, only self-objectification was a significant predictor of physical activity; it accounted for $27 \%$ of the variance. Table $\mathrm{V}$ includes the regression coefficients for both age groups. Although statistically significant predictors of physical activity were found, given the relatively small amount of variance accounted for, other variables clearly influence levels of physical activity.

Table V. Regression Coefficients for Stepwise Regression Analyses

\begin{tabular}{lllrrrr}
\hline & \multicolumn{7}{c}{ Physical activity } \\
\cline { 2 - 7 } & \multicolumn{1}{c}{$R^{2}$} & $\Delta R^{2}$ & $B$ & $S E B$ & $\beta$ & Sig \\
\hline Younger age group & & & & & & \\
Step 1. BMI & .00 & .000 & 0.008 & 0.646 & 0.010 & .901 \\
Step 2. BMI & $.03^{*}$ & .035 & -0.300 & 0.655 & -0.036 & .647 \\
$\quad$ Disordered eating & - & - & 0.286 & 0.115 & 0.193 & .014 \\
Step 3. BMI & $.09^{* *}$ & .092 & -0.412 & 0.638 & -0.049 & .519 \\
$\quad$ Disordered eating & - & - & 0.512 & 0.132 & 0.345 & .000 \\
$\quad$ Self-objectification & - & - & -7.348 & 2.267 & -0.281 & .001 \\
Older age group & & & & & & \\
Step 1. BMI & .02 & .000 & -0.130 & 0.666 & 0.018 & .029 \\
Step 2. BMI & $.27^{* *}$ & .071 & 0.000 & 0.646 & 0.000 & .996 \\
$\quad$ Self-objectification & - & -8.836 & 2.948 & 0.267 & .003 & - \\
\hline${ }^{*} p<.05 .{ }^{* *} p<.001$. & & & & & &
\end{tabular}




\section{DISCUSSION}

The purposes of this study were to examine (a) the mediation effects of body shame and flow on the relationship between self-objectification and disordered eating symptomology, (b) age differences in self-objectification, body shame, flow, and disordered eating symptomology, and (c) if and how selfobjectification, flow, body shame, and disordered eating accounted for variance in physical activity, and (d) the relationships among self-objectification, flow, body shame, disordered eating, and levels of physical activity.

Body shame partially mediated the relationship between self-objectification and disordered eating for both the younger and older women in the present study. The association of self-objectification with body shame and disordered eating supports previous research findings (Fredrickson et al., 1998; McKinley \& Hyde, 1996; Noll \& Fredrickson, 1998). This consistent finding (i.e., higher levels of selfobjectification are associated with higher levels of body shame and disordered eating) suggests the importance of self-objectification, regardless of age, in body experiences and resulting maladaptive behaviors. As Noll and Fredrickson (1998) pointed out, the fact that self-objectification is both directly and indirectly related to disordered eating behaviors highlights its importance and may be considered a risk factor in the development of disordered eating attitudes and behaviors.

Contrary to the Objectification Theory model proposed by Fredrickson and Roberts (1997), flow did not mediate the relationship between selfobjectification and disordered eating. Examining the relations among flow, self-objectification, and disordered eating versus the relationship among body shame, self-objectification, and disordered eating, it is evident that body shame was more strongly associated with the proposed predictor and criterion variables. While significant correlations were found between flow and self-objectification and disordered eating, the relationships were not strong enough for flow to mediate the relationship. Tiggemann and Slater (2001) similarly reported that body shame, but not flow, mediated the relationship between selfobjectification and disordered eating.

In line with previous research, age-related differences were found; the younger women reported higher levels of self-objectification, body shame, and dieting than did the older women. McKinley (1999), for example, similarly found that college women re- ported greater body surveillance and body shame than did their middle-aged mothers. Several researchers have suggested that as women age they become more comfortable with their bodies (Lamb, Jackson, Cassiday, \& Priest, 1993; Ransdell, Wells, Manore, Swan, \& Corbin, 1998; Tunaley, Walsh, \& Nicolson, 1999) and engage in less disordered eating (Heatherton, Mahamedi, Striepe, Field, \& Keel, 1997). As a potential explanation for age-related differences, McKinley (1999) has suggested that generational differences and sources of self-esteem are essential factors to consider. Generational differences may be a factor in that over time, social norms and body ideals have changed. For example, in the 1950s, Marilyn Monroe's voluptuous figure was the ideal, whereas in late 1990s Ally McBeal's extremely thin body was the ideal. Furthermore, during the 1960s and 1970s, the women's movement encouraged feminist ideologies and the rejection of social beauty ideals; today, however, young women may not feel that kind support for resisting cultural ideals of beauty (Rubin, Nemeroff, \& Russo, 2004). A second possible factor is women's sources of selfesteem. Younger women may gain their self-worth from their appearance, whereas middle age and older women may focus more on their accomplishments as a source of self-esteem.

In addition, older women scored higher than younger women on the loss of self-consciousness subscale of the FTS. Given that the older women reported lower levels of self-objectification and body shame than did the younger women, it is not surprising that they also indicated experiencing a loss of selfconsciousness during exercise more frequently than did the younger age women. The younger women in the present study, because they experienced higher levels of self-objectification and body shame, may have been less able to let go of body monitoring thoughts and concerns about how their body was being judged by others during exercise activities, whereas older women, who experienced lower levels of self-objectification and body shame, may have been more able to become absorbed in the task, thereby reducing feelings of self-consciousness. As Fredrickson and Roberts (1997) have suggested, women may have more opportunities to step away from the spotlight of objectification as they age, and these opportunities may make them more comfortable in exercise settings.

Regression analyses revealed that selfobjectification predicted levels of physical activity for both age groups. Although the exact nature 
of this association cannot be determined from the present study, this initial finding suggests that women who internalize an observer's view of their bodies and view their bodies as objects are less likely to be physically active. Limited research has been conducted to examine the relationship between self-objectification and physical activity, however, Wolfe (1999) found that self-objectifying thoughts were triggered during exercise and that women were particularly vulnerable to self-objectification while exercising. In addition, previous research findings do suggest that improving appearance is a major motive for exercise among women, which suggests a focus on one's physique and weight concerns related to reasons for exercise participation (McDonald \& Thompson, 1992; Silberstein, Striegel-Moore, Timko, \& Rodin, 1988). More recently, Strelan, Mehaffey, and Tiggemann (2003) confirmed that appearance-related motives for exercise were related to self-objectification. There is initial evidence, then, that self-objectification plays a role in women's participation in physical activity.

As an extension of previous research, flow experiences during physical activity were examined. The results indicate that both younger and older women high in self-objectification tended to have fewer flow experiences than did women low in selfobjectification. This is logical considering Jackson's (1995) research with elite athletes on factors that prevented or disrupted flow, including inappropriate focus and self-doubt. It seems that women high in self-objectification may experience more factors that either prevent them from getting into flow or more factors that disrupt flow experiences. Thus, focusing on one's body and worrying about how one's body will be evaluated by others may act to prevent or disrupt flow experiences. For example, an exercise environment that highlights or draws attention to the body (i.e., fitness rooms with mirrored walls, fitness instructors wearing tight fitting apparel) may heighten exercisers' awareness of their own physiques and result in increased self-objectification. Martin Ginis and colleagues (2003) found, for instance, that women felt worse after exercising in a mirrored environment than after exercising in a nonmirrored environment. Thus, although exercise may provide people with a sense of competence and thus have the potential to impact self-esteem and body image positively (Bartlewski, Van Raalte, \& Brewer, 1996; Riddick \& Freitag, 1984; Tucker \& Maxwell, 1992), it is possible that self-objectification may reduce the positive influence of exercise.

\section{Study Limitations}

As with all research, the present study has its limitations. First, the design of the study is nonexperimental, thus causal conclusions may not be drawn. The correlational nature of this design precludes any conclusions about the temporal nature of self-objectification and the other constructs examined. For example, it is not possible to determine if self-objectification leads to increased body shame or if body shame results in increased selfobjectification. Future researchers should seek to determine which factors are antecedents and which factors are consequences of the constructs included in Objectification Theory (Fredrickson \& Roberts, 1997). Second, the present study focused on selected variables within the self-objectification framework. Thus, there are other variables (e.g., ethnicity, sexual orientation, sensitivity to bodily cues, and control beliefs) that could influence the relationships examined in the present study that will need to be studied in future research. Third, because self-report data were used in this study, participants may have responded in a socially desirable manner even though anti-social desirability instructions (i.e., "Please answer honestly. All responses will be kept confidential and will only be seen by the primary investigator") were used. Finally, the age-group comparison conducted was cross-sectional in nature, thus certain threats to the internal validity of the study, such as selection bias, need to be recognized.

\section{Conclusions and Future Directions}

Further examination of how self-objectification is related to exercise participation may provide information important for understanding women's healthrelated behaviors. Especially needed is intervention research to examine strategies for reducing selfobjectification and body shame that could result in the reduction of disordered eating attitudes and behaviors and an increase in physical activity. In addition, as most previous body concern and disordered eating research and models have been developed with college aged women, future research is warranted to examine more specifically the experiences of self-objectification and various body concerns among older women to determine if and how the Objectification Theory model is a useful theoretical model and framework. For example, it may be the case that as women age they are somehow better 
able to cope with experiences that have the potential to heighten self-objectification in ways that allow them to focus not on their bodies and appearance but on other factors such as accomplishment and enjoyment. Thus far, researchers have not thoroughly examined why such differences exist between younger and older women.

Many feminist scholars and researchers have argued that women's lives will be negatively impacted as long as society pressures women to appear a certain way and evaluates women's worth according to how well they fit the beauty ideal (Grogan, 1999; McKinley, 1999). McKinley and Hyde (1996) suggested that calling attention to self-objectification and related constructs is important because it allows women the think about how negative body experiences could be changed. The objectification of women's bodies must be reduced before positive body images can be developed (Grogan, 1999; Wolf, 1991). Grogan (1999) stated that "[w]e need to resist the objectification of the body in general, and in particular the cultural expectation that women's bodies should conform to an ideal that is unattainable to most women" (p. 191). Although this sentiment is easily said and agreed with, it is quite difficult to accomplish in a culture where "thin is in."

\section{ACKNOWLEDGMENTS}

Appreciation is extended to Dr. Gould and to my committee members, Drs. Diane Gill, Thomas Martinek, and Lloyd Bond, for their assistance. Thanks also to Dr. Tammy Schilling for feedback provided on an earlier draft of this manuscript. This study was supported in part by the Susan Stout Graduate Research Award.

\section{REFERENCES}

Altabe, M., \& Thompson, J. K. (1993). Body image changes during early adulthood. International Journal of Eating Disorders, 13, 323-328.

Baron, R. M., \& Kenny, D. A. (1986). The moderator-mediator variable distinction in social psychological research: Conceptual, strategic, and statistical consideration. Journal of Personality and Social Psychology, 51, 1173-1182.

Bartlewski, P. P., Van Raalte, J. L., \& Brewer, B. W. (1996). Effects of aerobic exercise on the social physique and body esteem of female college students. Women in Sport and Physical Activity Journal, 5, 49-62.

Ben-Tovim, D. I., \& Walker, M. K. (1994). The influence of age and weight on women's body attitudes as measured by the Body Attitudes Questionnaire (BAQ). Journal of Psychosomatic Research, 38, 477-481.
Bordo, S. (1993). Unbearable weight: Feminism, Western culture, and the body. Berkeley, CA: University of California Press.

Cash, T. F., Winstead, B. A., \& Janda, L. (1986, April). The great American shape up. Psychology Today, pp. 30-37.

Csikszentmihalyi, M. (1990). Flow: The psychology of optimal experience. New York: Harper and Row.

Cusumano, D. L., \& Thompson, J. K. (1997). Body image and body shape ideals in magazines: Exposure, awareness, and internalization. Sex Roles, 37, 701-721.

Davis, C., \& Cowles, M. (1991). Body image and exercise: A study of relationships and comparisons between physically active men and women. Sex Roles, 25, 33-44.

Focht, B., \& Hausenblas, H. A. (2003). State anxiety responses to acute exercise in women with high social physique anxiety. Journal of Sport and Exercise Psychology, 25, 123-144.

Fredrickson, B. L., \& Roberts, T. A. (1997). Objectification theory: Toward understanding women's lived experiences and mental health risks. Psychology of Women Quarterly, 21, 173-206.

Fredrickson, B. L., Roberts, T. A., Noll, S. M., Quinn, D. M., \& Twenge, J. M. (1998). That swimsuit becomes you: Sex differences in self-objectification, restrained eating, and math performance. Journal of Personality and Social Psychology, 75, 269-284.

Gapinski, K. D., Brownell, K. D., \& LaFrance, M. (2003). Body objectification and "fat talk": Effects on emotion, motivation, and cognitive performance. Sex Roles, 48, 377-388.

Garner, D. M. (1997, January/Febrary). The 1997 body image survey. Psychology Today, pp. 30-44.

Garner, D. M., Olmsted, M. P., Bohr, Y., \& Garfinkel, P. E. (1982). The Eating Attitudes Test: Psychometric features and clinical correlates. Psychological Medicine, 12, 871-878.

Grogan, S. (1999). Body image: Understanding body dissatisfaction in men, women, and children. London: Routledge.

Heatherton, T. F., Mahamedi, F., Striepe, M., Field, A. E., \& Keel, P. (1997). A 10-year longitudinal study of body weight, dieting, and eating disorder symptoms. Journal of Abnormal Psychology, 106, 117-125.

Holmbeck, G. N. (1997). Toward terminological, conceptual, and statistical clarity in the study of mediators and moderators: Examples from the child-clinical and pediatric psychology literatures. Journal of Consulting and Clinical Psychology, 65, 599-610.

Jackson, S. A. (1995). Factors influencing the occurrence of flow state in elite athletes. Journal of Applied Sport Psychology, 7, 138-166.

Jackson, S. A., \& Csikszentmihalyi, M. (1999). Flow in sports: The keys to optimal experiences and performances. Champaign, IL: Human Kinetics.

Jackson, S. A., \& Eklund, R. C. (2002). Assessing flow in physical activity: The Flow State Scale-2 and Dispositional Flow Scale-2. Journal of Sport and Exercise Psychology, 24, 133150.

Jackson, S. A., Kimiecik, J. C., Ford, S. K., \& Marsh, H. W. (1998). Psychological correlates of flow in sport. Journal of Sport and Exercise Psychology, 20, 358-378.

Jackson, S. A., \& Marsh, H. W. (1996). Development and validation of a scale to measure optimal experience: The Flow State Scale. Journal of Sport and Exercise Psychology, 18, 1735.

Kohl, H. W., Blair, S. N., Paffenbarger, R. S., Macera, C. A., \& Kronenfeld, J. J. (1988). A mail survey of physical activity habits as related to measured physical fitness. American Journal of Epidemiology, 127, 1228-1239.

Lamb, C. S., Jackson, L., Cassiday, P., \& Priest, D. (1993). Body figure preferences of men and women: A comparison of two generations. Sex Roles, 28, 345-358.

Leary, M. (1992). Self-presentation processes in exercise and sport. Journal of Sport and Exercise Psychology, 14, 339351. 
Martin Ginis, K. A., Jung, M. E. \& Gauvin, L. (2003). To see or not to see: Effects of exercising in mirrored environments on sedentary women's feeling states and self-efficacy. Health Psychology, 22, 354-236.

McDonald, K., \& Thompson, J. K. (1992). Eating disturbance, body image dissatisfaction, and reasons for exercising: Gender differences and correlational findings. International Journal of Eating Disorders, 11, 289-292.

McKinley, N. M. (1999). Women and objectified body consciousness: Mothers' and daughters' body experience in cultural, developmental, and familial context. Developmental Psychology, 35, 760-769.

McKinley, N. M., \& Hyde, J. S. (1996). The Objectified Body Consciousness Scale: Development and validation. Psychology of Women Quarterly, 20, 181-215.

Muehlenkamp, J. J., \& Saris-Baglama, R. N. (2002). Selfobjectification and its psychological outcomes for college women. Psychology of Women Ouarterly, 26, 371-379.

Noll, S. M., \& Fredrickson, B. L. (1998). A mediational model linking self-objectification, body shame, and disordered eating. Psychology of Women Quarterly, 22, 623-636.

Oliveria, S. A., Kohl, H. W., Trichopoulos, D., \& Blair, S. N. (1996). The association between cardiorespiratory fitness and prostate cancer. Medicine and Science in Sports and Exercise, $28,97-104$.

Pliner, P., Chaiken, S., \& Flett, G. L. (1990). Gender differences in concern with body weight and physical appearance over the life span. Personality and Social Psychology Bulletin, 16, 263273.

Rand, C. S., \& Kuldau, J. M. (1991). Restrained eating (weight concerns) in the general population and among students. International Journal of Eating Disorders, 10, 699-708.

Ransdell, L. B., Wells, C. L., Manore, M. M., Swan, P. D., \& Corbin, C. B. (1998). Social physique anxiety in postmenopausal women. Journal of Women and Aging, 10, 19-39.

Riddick, C. C., \& Freitag, R. S. (1984). The impact of an aerobic fitness program on the body image of older women. Activities, Adaptation, and Aging, 6, 59-70.
Roberts, T. A., \& Gettman, J. Y. (2004). Mere exposure: Gender differences in the negative effects of priming a state of selfobjectification. Sex Roles, 51, 17-27.

Rozin, P., \& Fallon, A. (1988). Body image, attitudes toward weight, and misperceptions of figure preferences of the opposite sex: A comparison of men and women in two generations. Journal of Abnormal Psychology, 97, 342-345.

Rubin, L. R., Nemeroff, C. J., \& Russo, N. F (2004). Exploring feminist women's body consciousness. Psychology of Women Quarterly, 28, 27-37.

Silberstein, L. R., Striegel-Moore, R. H., Timko, C., \& Rodin, J. (1988). Behavioral and psychological implications of body dissatisfaction: Do men and women differ? Sex Roles, 19, 219 232.

Slater, A., \& Tiggemann, M. (2002). A test of objectification theory in adolescent girls. Sex Roles, 46, 343-349.

Strelan, P., Mehaffey, S. J., \& Tiggemann, M. (2003). Selfobjectification and esteem in young women: The mediating role of exercise. Sex Roles, 48, 89-95.

Tiggemann, M., \& Lynch, J. E. (2001). Body image across the life span in adult women: The role of self-objectification. Developmental Psychology, 37, 243-253.

Tiggemann, M., \& Slater, A. (2001). A test of objectification theory in former dancers and nondancers. Psychology of Women Quarterly, 25, 57-64.

Tucker, L. A., \& Maxwell, K. (1992). Effects of weight training on the emotional well-being and body image of females: Predictors of greatest benefit. American Journal of Health Promotion, 6, 338-344.

Tunaley, J. R., Walsh, S., \& Nicolson, P. (1999). 'I'm not bad for my age': The meaning of body size and eating in the lives of older women. Ageing and Society, 19, 741-759.

Wolf, N. (1991). The beauty myth: How images of beauty are used against women. New York, NY: Doubleday.

Wolfe, R. (1999). Body-objectifying thoughts: Impact on mood change during exercise (Doctoral dissertation, Duke University, 1999). Dissertation Abstracts International, 60(1-B), 0379 . 